\title{
Forensic study of structures for durability
}

\author{
M. Holický \\ Czech Technical University in Prague, Klokner Institute, Czech Republic
}

\begin{abstract}
Structural durability is becoming an important issue of forensic engineering. General principles on probabilistic approach to structural design for durability are provided in a newly developing international standard ISO "General Principles on the Design of Structures for Durability". It appears, however, that the operational use of the new procedures in practice would require additional studies focussed primarily on forensic criteria, physical models of material deteriorations, and theoretical models of basic variables. It is shown that forensic criteria should be differentiated taking into account the character of the relevant limit state, consequences of its infringement and costs of safety measures. Three limit states are distinguished in general: initiation limit state, serviceability limit state and ultimate limit state. Probabilistic methods of cost optimisation are used to provide background information facilitating specification of appropriate target reliability levels. General principles on forensic assessment of structures for durability are illustrated on an example of a reinforced concrete members exposed to carbonation. It is shown that the total cost of the member including cost of durability failure depends on the thickness of the concrete cover, design service life and discount rate. The optimum concrete cover increases
\end{abstract}

Keywords: assessment, durability, service life, optimisation, target reliability.

\section{Introduction}

Structural durability is becoming an important issue of forensic engineering. General principles on probabilistic approach to structural design for durability are provided in a number of international documents (CEB [1], EN 1990 [2], Fib [3]), several studies (Holický and Mihashi [4], Holický and Holická [5] and in a newly developing international standard ISO 13823 [6] "General Principles on the Design of Structures for Durability". It is expected that the document ISO 13823 [6] will be soon completed and then implemented into the systems of 
national standards. It appears, however, that the operational use of the new procedures in practice would require additional studies focussed primarily on forensic criteria, physical models of material deteriorations, and theoretical models of basic variables.

The technical committee TC 98 of the International organisation for Standardisation ISO has been preparing a new document on structural design ISO 13823 [6] provisionally entitled "General Principles on the Design of Structures for Durability". The document is based on the fundamental principles provided in recent international documents CEB [1], ISO 2394 [7], ISO 19338 [8] and EN 1990 [2]. Materials of other international organisations as CEB [1] and RILEM [11] and other publications (for example Holický and Mihashi [4], Holický and Holická [5], Kasami et al. [9], Norami [10]) have also been taken into account. References to other ISO/IEC materials and to a number of particular studies are provided in the upcoming document ISO 13823 [6].

It is shown that forensic criteria should be differentiated taking into account the character of the relevant limit state, consequences of its infringement (malfunctioning costs) and costs of safety measures. Three limit states are distinguished in general: durability (initiation) limit state, serviceability limit state and ultimate limit state. Probabilistic methods of cost optimisation are used to provide background information facilitating specification of appropriate target reliability levels. General principles on forensic assessment of structures for durability are illustrated on an example of a reinforced concrete members exposed to carbonation.

\section{Limit states concept}

The document ISO 13823 [6] formulates the principles of limit state methods for durability. The key steps of the deterioration processes and reliability verification using the concepts of limit states are indicated in Figure 1 adopted from the document ISO 13823 [6].

It should be noted that Figure 1 is a result of many discussions and amendments made during the development of the document ISO 13823 [6] and it might still be slightly changed. It is, however, a very general scheme that may be, in a particular application, modified depending on the actual conditions of a considered structure.

There are three vertical strands in Figure 1, time axis on the left, reality in the middle and professional practice on the right. The time axis is split into two parts by a point denoted as Durability Limit State (DLS). The term "Durability Limit State" is adopted from another ISO document ISO 19338 [8]. It corresponds to the point in time when environment actions (the development of unfavourable processes) have turning point (for example the beginning of reinforcement corrosion or decays of construction materials).

The middle part of Figure 1 indicates a sequence of real processes: "Structural Environment" and influences (rain, de-icing salts and other agents), "Transfer mechanisms" of environmental influences and "Environmental effects" (reinforcement corrosion, material decay). In the right part of Figure 1 it is 
indicated that the transfer mechanisms be described by models or tests. Two types of models are generally distinguished: Conceptual (heuristic) model, specified on the bases of reasoning and previous experience, and mathematical (analytical) model, specified on the basis of theoretical assumptions, for example concerning diffusion processes.

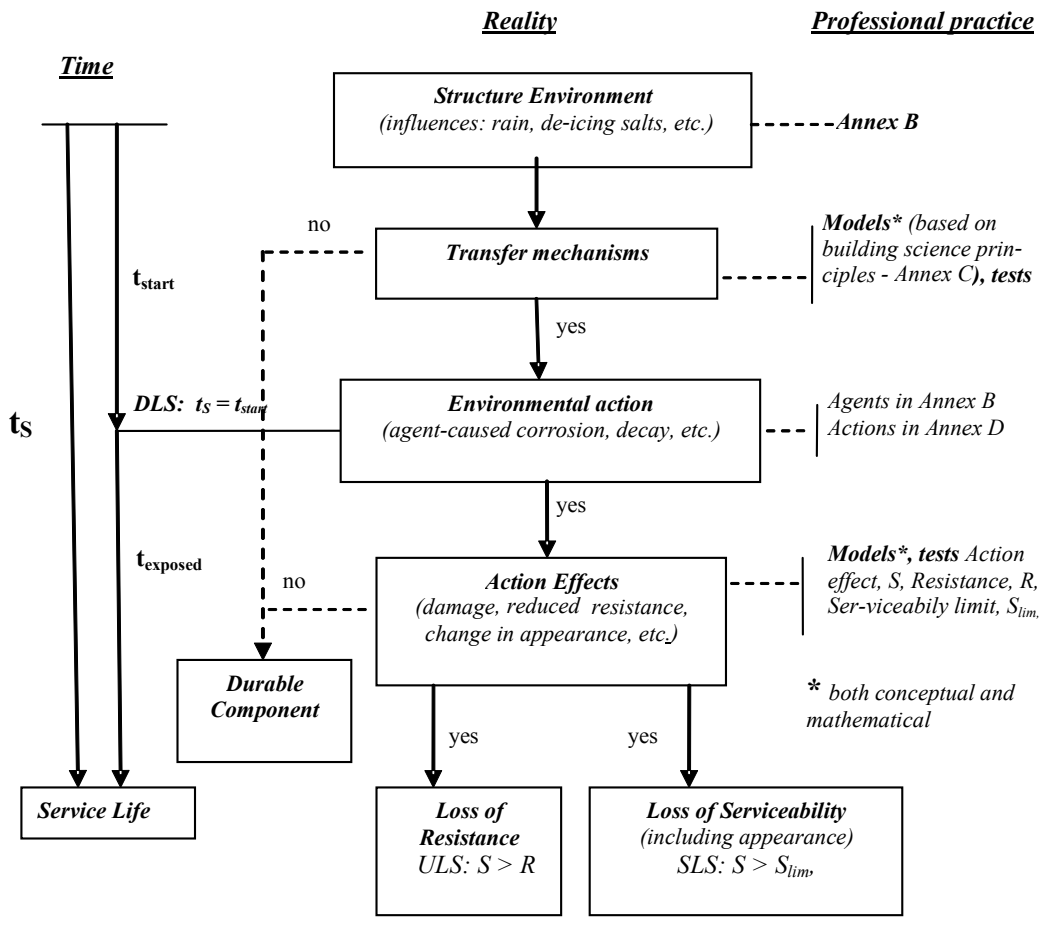

Figure 1: $\quad$ Limit state method for durability.

The environmental effects may in general be combined with the action effects (the middle part of Figure 1). Resulting effects may then lead to the loss of resistance (bearing capacity) of structures or to the loss of serviceability (an excessive width of cracks or deformation). These limit states - ULS and SLS are indicated in the lower part of Figure 1. However, an important question of load combination rules is not covered in ISO 13823 (2006) [6].

\section{Verification of the service life}

The fundamental durability requirement is represented by a simple condition that the predicted service life $t_{\mathrm{SP}}$ should be greater than the design service life $t_{\mathrm{D}}$ with a sufficient degree of reliability. Difficulties are obviously linked to the term "sufficient reliability". It is well recognised that the service life $t_{\mathrm{S}}$ is dependent on a number of basic variables and is consequently a random variable having a 
considerable scatter. The document ISO 13823 [6] therefore provides a probabilistic formulation of this criterion in the form

$$
\mathrm{P}\left\{t_{\mathrm{S}}<t_{\mathrm{D}}\right\}<P_{\text {target }}
$$

Here $P_{\text {target }}$ denotes the target probability of the service life $t_{\mathrm{S}}$ being less than the design service life $t_{\mathrm{D}}$. As a rule the design service life $t_{\mathrm{D}}$ is a deterministic quantity (for example 50 or 100 years) specified in advance.

\section{Verification of the limit states}

The probabilistic formulation of the limit states conditions is similar as in case of the service life. For an arbitrary point in time $t \leq t_{\mathrm{D}}$ the following condition should be valid

$$
\mathrm{P}_{\mathrm{f}}(t)=\mathrm{P}\{R(t)-S(t)<0\}<P_{\text {target }}
$$

where $R(t)$ denotes resistance and $S(t)$ action effect.

The basic probabilistic condition for the serviceability may be written analogously as

$$
\mathrm{P}_{\mathrm{f}}(t)=\mathrm{P}\left\{S_{\text {lim }}-S(t)<0\right\}<P_{\text {target }}
$$

Here $S_{\text {lim }}$ denotes the limit value of the serviceability indicator (for example of the crack width or deflection). The durability limit state (DLS) may be verified in accordance with Equations (2) or (3) depending on the particular conditions.

The probabilistic assessment of the service life called predicted service life $t_{\mathrm{SP}}$ is schematically shown in Figure 2 adopted from ISO 13823 [6] similarly as Figure 1. It should be emphasized that Figure 2 only monotonously describes

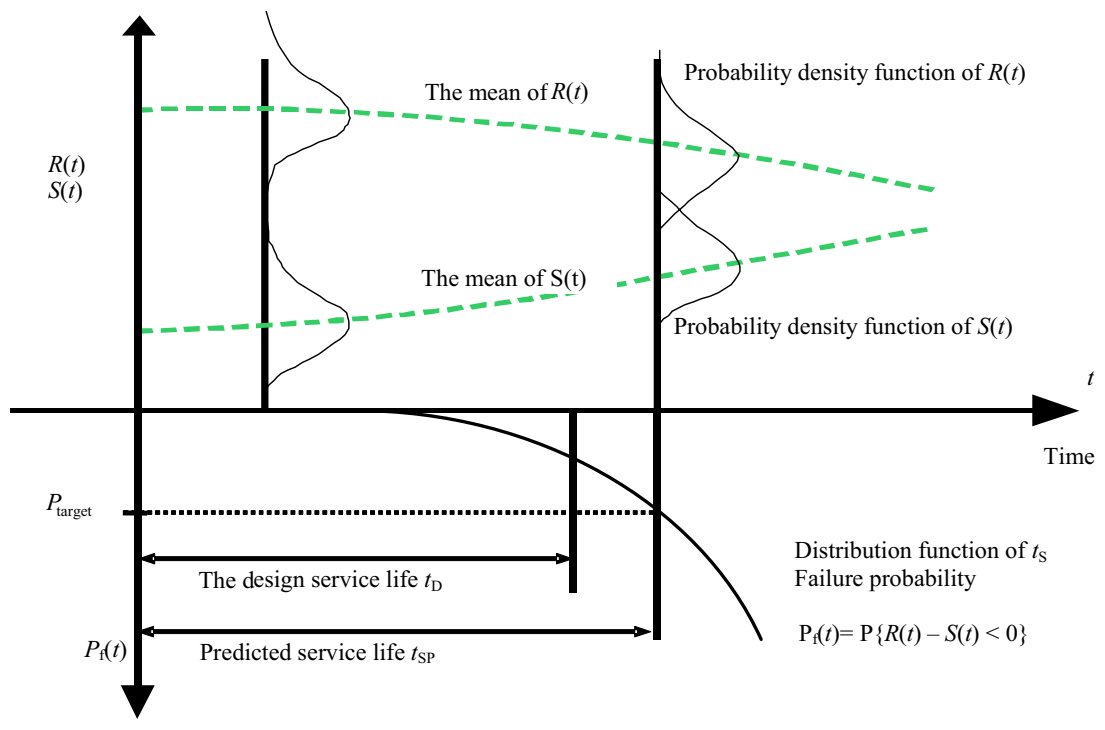

Figure 2: $\quad$ Probabilistic assessment of the service life. 
varying action effects $S(t)$ and resistances $R(t)$. The horizontal axis denotes the time $t$ and the vertical axis in the upper part denotes the resistance $R(t)$ or action effect $S(t)$, in the lower part the probability $\mathrm{P}_{\mathrm{f}}(t)$.

Obviously the failure probability $\mathrm{P}_{\mathrm{f}}(t)=\mathrm{P}\{R(t)-S(t)<0\}$ is an increasing function time $t$. The predicted service life $t_{\mathrm{SP}}$ then follows from the relationship

$$
\mathrm{P}_{\mathrm{f}}\left(t_{\mathrm{SP}}\right)=\mathrm{P}\{R(t)-S(t)<0\}=P_{\text {target }}
$$

Probability distributions of the variables $R(t)$ and $S(t)$ are in Figure 2 indicated by probability density functions. However, there are no recommendations concerning the target probability $P_{\text {target }}$ provided in the document ISO 13823 [6] and this open question may cause difficulties in the effective use of the document.

\section{Target reliability level}

Target reliability level, indicated by the target probability $P_{\text {target }}$ or reliability index $\beta_{\text {target }}$, depends in general on the definition of the service life time, whether the critical durability requirement concerns the ultimate limit state, serviceability limit state or durability limit state and depends also on what are the consequences of their infringement. In particular conditions the target reliability level may considerably vary. Table 1 provides indicative intervals for the target probability $P_{\text {target }}$ and reliability index $\beta_{\text {target }}$, which are not given in the upcoming document ISO 13823 [6].

Table 1: $\quad$ Indicative values of the target probability $P_{\text {target }}$ and index $\beta_{\text {target }}$.

\begin{tabular}{|l|c|c|}
\hline Limit state & $P_{\text {target }}$ & $\beta_{\text {target }}$ \\
\hline Ultimate limit state - ULS & $\sim 10^{-4}$ & $\sim 3,7$ \\
\hline Serviceability limit state - SLS & 0,01 to 0,10 & 1,3 to 2,3 \\
\hline Durability limit state - DLS & 0,05 to 0,20 & 0,8 to 1,6 \\
\hline
\end{tabular}

The target probability $P_{\text {target }}$ and reliability index $\beta_{\text {target }}$ given in Table 1 represent indicative values only. They are derived from the target values recommended in EN 1990 [2] and ISO 2394 [7]. It should be mentioned that ISO 2394 [7] indicates an additional dependence of the target values on relative costs of safety measures (required for an increase of the reliability level). This aspect should be also considered when specifying target reliability level for durability requirements. Specification of the appropriate reliability level remains therefore one of the most important open questions.

\section{An example of the durability limit state}

The durability limit state DLS can be well illustrated by the carbonation of concrete. The limit state is defined as a simple requirement that the carbonation 
depth $S(t)$ (action effect) is less than the concrete cover $R$ (resistance). Failure probability can be then determined using Equation (2) from the integral

$$
P_{\mathrm{f}}(t)=P\{S(t)>R\}=\int_{-\infty}^{\infty} \varphi_{S}(x, t) \Phi_{R}(x) \mathrm{d} x
$$

where $\varphi_{S}(x, t)$ denotes the probability density function of the action effect $S(t)$ and $\Phi_{R}(x)$ the distribution function of the resistance $R$.

Extensive measurements of the carbonation depth $S(t)$ on cooling towers Holický and Mihashi [4] (unprotected external concrete) provided the following expressions for the mean $\mu_{S}(t)$, coefficient of variation $w_{S}(t)$ and skewness $\alpha_{S}(t)$

$$
\mu_{S}(t)=5 t^{0,2} \mathrm{~mm}, w_{S}(t)=0,1 t^{0,2}, \alpha_{S}(t)=0,2 t^{0,2}
$$

where $t$ denotes time in years. Gamma distribution seems to be the most suitable theoretical model.

For a time-invariant concrete cover the following parameters have been obtained

$$
\mu_{R}=20,25 \text { a } 30 \mathrm{~mm}, w_{R}=0,35 \mathrm{~mm}, \alpha_{R}=0,35
$$

In that case Beta distribution having the lower bound at zero seems to be a suitable theoretical model. Note that in Annex A of ISO 13823 [6] a normal distribution is assumed for both variables $S(t)$ and $R$; this assumption may provide a first approximation only.

Considering the above mentioned theoretical models and their parameters given in Equations (6) and (7) the failure probability $P_{\mathrm{f}}(t)$ given by Equation (5) is shown in Figure 3. Figure 3 can be used to assess the service life $t_{\mathrm{SP}}$ defined by Equation (4) for a specified target probability $P_{\text {target }}$ and the mean of concrete

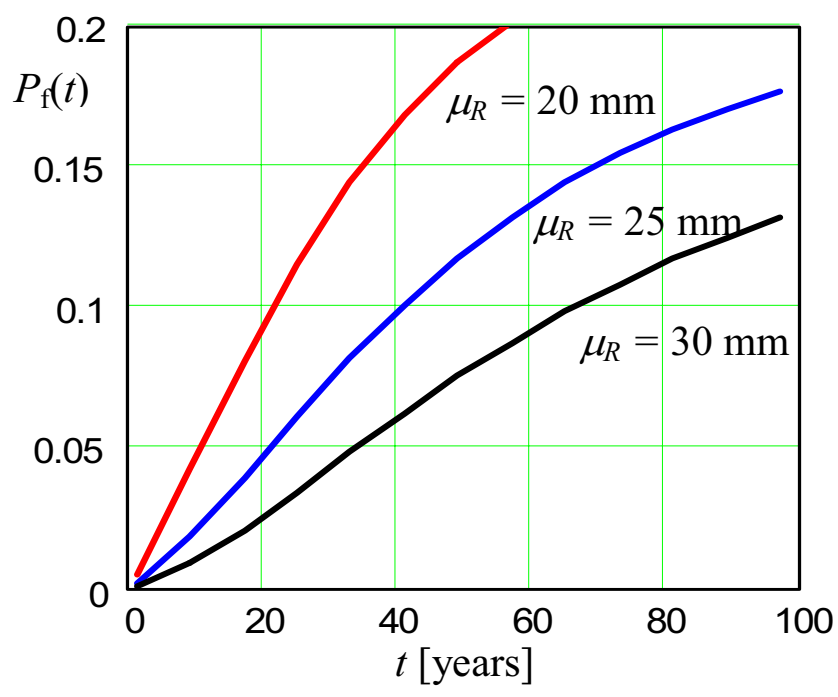

Figure 3: Probability $\mathrm{P}_{\mathrm{f}}(t)=\mathrm{P}\{S(t)>R\}$ for parameters in Equations (6) and (7). 
cover $\mu_{R}$. If, for example, $P_{\text {target }}=0,10$, then the mean $\mu_{R}=20 \mathrm{~mm}$ corresponds to $t_{\mathrm{SP}} \sim 23$ years, if $\mu_{R}=30 \mathrm{~mm}$, then $t_{\mathrm{SP}} \sim 65$ let. Figure 3 confirms the results of previous studies by Holický and Mihashi [4], Holický and Holická [5], which indicates that the assessment of $t_{\mathrm{SP}}$ is significantly dependent on theoretical models assumed for $R(t)$ and $S(t)$, and on the specified target probability $P_{\text {target }}$.

It appears, that methods of probabilistic analysis may be effectively used for the specification of the target reliability level and forensic assessment of structures.

\section{Probabilistic optimisation}

The total costs of execution and repair of the structure due to failure (infringement of the durability limit state) can be expressed as a function of the mean $\mu_{R}$ (decisive parameter)

$$
C_{\mathrm{tot}}\left(\mu_{R}, t, p\right)=C_{0}+C_{1} \mu_{R}+\mathrm{P}_{\mathrm{f}}\left(\mu_{R}, t\right) C_{\mathrm{f}} /(1+p)^{t}
$$

where $C_{0}$ denotes the initial costs independent of $\mu_{R}, C_{1}$ expenses for a unit of $\mu_{R}$, $C_{\mathrm{f}}$ expenses for the durability failure and $p$ the discount rate (around 0,03). Standardised total cost is considered as

$$
\kappa_{\mathrm{tot}}\left(\mu_{R}, t, p\right)=\left[C_{\mathrm{tot}}\left(\mu_{R}, t, p\right)-C_{0}\right] / C_{1}=\mu_{R}+P_{\mathrm{f}}\left(\mu_{R}, t\right) C_{\mathrm{f}}\left[\left[(1+p)^{t} C_{1}\right]\right.
$$

The optimum mean $\mu_{R}$ may be then determined from

$$
\frac{\partial \kappa_{\mathrm{tot}}\left(\mu_{R}, t, p\right)}{\partial \mu_{R}}=0
$$

Taking into account Equation (9) the following condition may be derived

$$
\frac{\partial P_{f}\left(\mu_{R}, t\right)}{\partial \mu_{R}}=-\frac{(1+p)^{t} C_{1}}{C_{f}}
$$

Note that within a realistic domain of $\mu_{R}$ from 20 do $60 \mathrm{~mm}$ Equation (11) may not have a practical solution and the minimum of the total costs may not be attained.

Considering the above described durability limit state, the standardised total costs $\kappa_{\mathrm{tot}}\left(\mu_{R}, t, p\right)$ given by Equation (9) are shown in Figure 4 assuming the design life time $t=50$ years and the discount rate $p=0,03$.

It appears that the optimum mean $\mu_{R}$ increases with increasing the cost ratio $C_{\mathrm{f}} / C_{1}$. For $C_{\mathrm{f}} / C_{1}=200$ the optimum $\mu_{R}$ is about $18 \mathrm{~mm}$ (a theoretical minimum is therefore less than $20 \mathrm{~mm}$ ), for the cost ratio $C_{\mathrm{f}} / C_{1}=1000$ the optimum mean is much greater, $\mu_{R} \sim 34 \mathrm{~mm}$. Interactive dependence of the total costs $\kappa_{\mathrm{tot}}\left(\mu_{R}, t, p\right)$ on $\mu_{R}$ and $p$ is shown in Figure 5 assuming the cost ratio $C_{\mathrm{f}} / C_{1}=1000$ and the design life time $t=50$ years. 


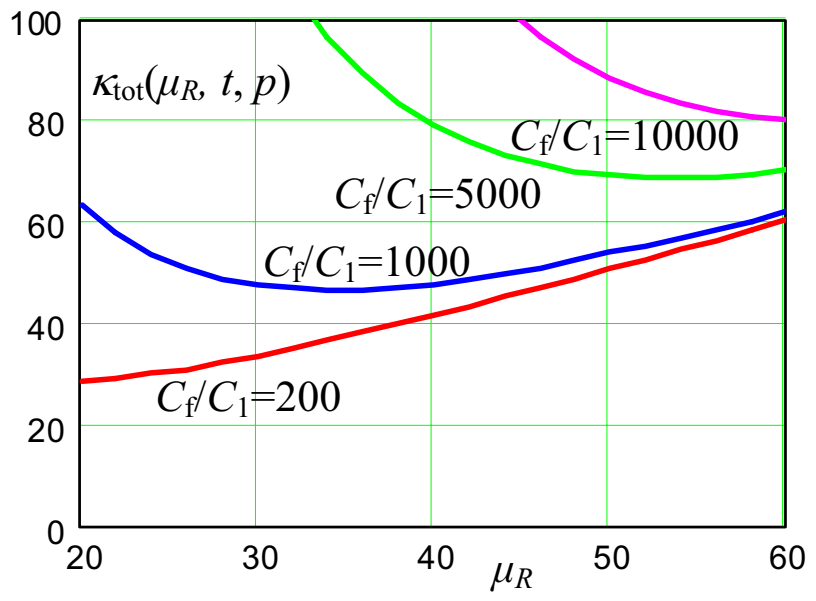

Figure 4: The total standardised costs $\kappa_{\mathrm{tot}}\left(\mu_{R}, t, p\right)$ for $t=50$ years and $p=0,03$.

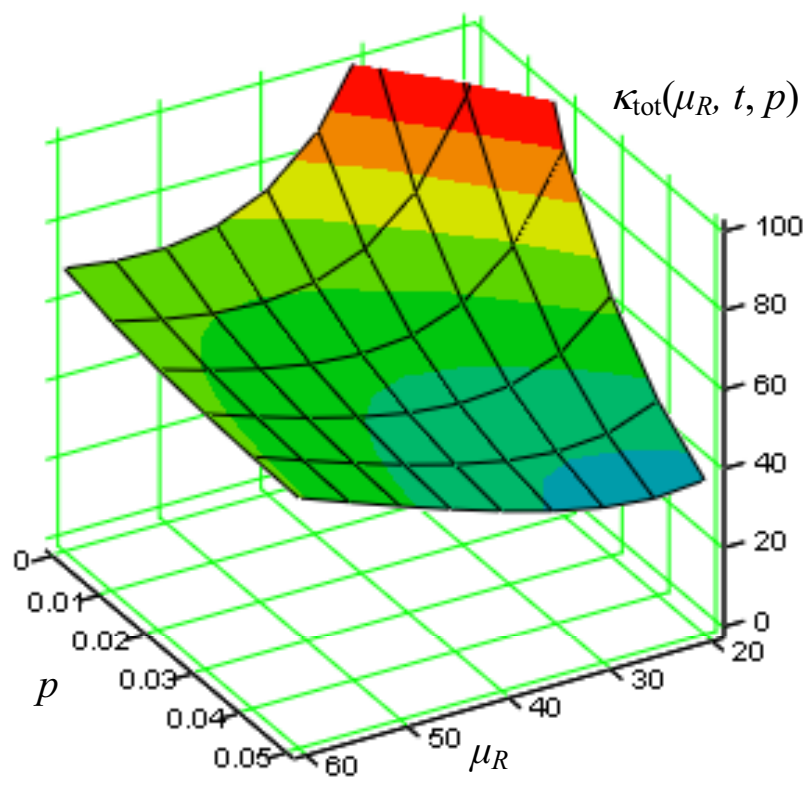

Figure 5: The total standardised costs $\kappa_{\mathrm{tot}}\left(\mu_{R}, t, p\right)$ for $C_{\mathrm{f}} / C_{1}=1000$, $t=50$ years.

Figure 5 clearly indicates that the discount rate $p$ may significantly affect the total costs and the optimum mean $\mu_{R}$. In addition also the design life time $t$ may affect the optimum concrete cover. These aspects can be decisive in a forensic assessment of concrete structures. 


\section{Concluding remarks}

Structural durability is becoming an important part of forensic assessment of buildings and other civil engineering works. Methods of probabilistic analysis and optimization may provide rational background information for a specification of the target reliability level. In case of carbonation of a concrete cover the total costs depend on the thickness of the concrete cover, design service life and discount rate.

The following particular conclusions may be drawn from the optimization study of a concrete cover.

- The optimum thickness of a concrete cover is significantly dependent on the cost ratio $C_{\mathrm{f}} / C_{1}$, specified design life and discount rate.

Commonly used concrete covers of reinforced concrete structures correspond to relatively low cost ratios $C_{\mathrm{f}} / C_{1}$.

For the required design life of 50 years, discount rate 0,03 and the low cost ratio $C_{\mathrm{f}} / C_{1}=200$, the optimum concrete cover is about $18 \mathrm{~mm}$, for the cost ratio $C_{\mathrm{f}} / C_{1}=1000$ the optimum cover is about $35 \mathrm{~mm}$.

Further experimental data and appropriate theoretical models for the carbonation process including the description of wetting and drying effects in outdoor conditions are needed.

Further studies on all the components of expected costs including marginal and costs due to protection failure are needed.

\section{Acknowledgement}

This study is a part of the research project GAČR 103/09/0693 “Assessment of Safety and Risks of Technical Systems".

\section{References}

[1] CEB. 1997. Bulletin d' Information No. 238 New Approach to Durability Design. An example for carbonation induced corrosion.

[2] EN 1990. 2002. Eurocode - Basis of structural design. CEN 2002.

[3] Fib. 2004. TG 5.6: Model Code for Service Life Design (SLD), working materials.

[4] Holický M. and Mihashi H. 2000. Stochastic Optimisation of Concrete Cover Exposed to Carbonation. In: R.E. Melchers \& Mark G. Steward (ed.), Application of Statistics and Probability. A. A. Balkema Rotterdam, pp. 279-284.

[5] Holický M. and Holická N. 2006. Probabilistic optimisation of concrete cover exposed to carbonation. Proc. of the International RILEM-JCI Seminar. pp. 384-393.

[6] ISO 13823. 2006. General Principles on the Design of Structures for Durability. ISO TC98/SC2, Draft 10. 2006.

[7] ISO 2394. 1998. General principles on reliability for structures. ISO. 
12 Safety and Security Engineering III

[8] ISO 19338. 2003. Performance and assessment requirements for design on structural concrete. 2003.

[9] Kasami, H., Izumi, I., Tomosawa, F. and Fukushi, I. 1986. Carbonation of concrete and corrosion of reinforcement in reinforced concrete, Proc. of First Australia-Japan Coordinated Workshop on Durability of Reinforced Concrete, Building Research Institute, Japan, C4, pp.1-13, October 1986.

[10] Norami T. 1996. Service life design. Construction and Building Materials, vol.10, no 5, 1996, 403-406

[11] RILEM. 1997. REPORT 14 Durability Design of Concrete Structures, Edited by Sarja A. and Vesikari E., E \& FN SPON, London, pp 165. 